Maldane's observations on mice are not entirely in aceord with those of the author of this paper. The reasons are probably, as already stated, dif-
forences in observation. The authors are convinced from their experiments that in a mine with poor from their experiments that in a mine with poor
light, and perhaps only hurried examination of the light, and perhaps only hurried examination of the
animal, and by persons more or less inexperienced animal, and by persons more or less inexperienced
in the actions of the animals, mice and canaries will not usually show distress pronounced enough to give good warning with 0.10 per cent or less of (arbon monoxide. Haldane's work shows that thi prreenlage may finally affect men, a headache in palpitations in less time. This condition will be palpitateras time. This condition will be unstearliness of movement. At the end of 20 minutes unsteadiness of movement. At the ond of 20 minutes
the author had only a slight headache when he the author had only a slight headache when he
cxposed himself to 0.25 per cent carbon monoxide (in air). Later, however, he became very ill. Canaries collapsed in just a few minutes.

In connection with the above laboratory experiments the author has made observations regarding is noteworthy, as follows:

1 mine fire recently occurred and a sample of mine gas was obtained that contained the following constituents:

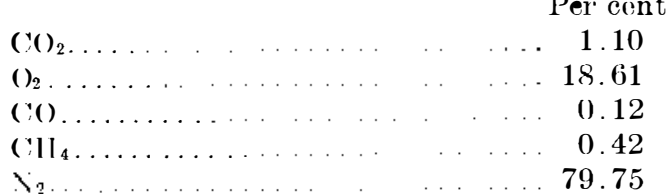
Total
100.00

This sample was obtained in a place where exploration work was being conducted. Canaries carried with the party were not affected but two of the men
finally complained of a bad headarhe. Later when they went to the surface they became ill. One was indisposed all cvening.

'lliese facts, although they appear damaging against the use of small animals for the purpose proposed, only militate in part against their usefulness. Such animals still remain, in the authors' opinion, the best indieators we have of vitiated air in mines. Canaries will give ample warning of percentages of carbon monoxide immediately dangerous to men. When the proportion of carbon monoxide is 0.15 per acnt, canaries will show distress usually in from 5 to 12 minutes. With 0.20 per cent the distress is apparent, usually in from 2 to 6 minutes. For distress to appear in men with these percentages requires much longer time, although in the case of some individuals the effects may, when they do appeiar, last for hours. The author has also determined this point experimentally, as have others. Men cannot stand the exposure to collapse from carbon monoxide as animals can. Canaries and mice after fresh air, only a matter of minutes usually. In the case of men exposed to collaspse, recovery is of ten a matter of days.

In assigning roasons for the different effects produced on men and small animals by small quanti-

\section{The Value of Science} By John W. N. Sullivan

THE word "value" is a highly ambiguous term, and in using the word its meaning should always be clearly defined. When a typical commercial man, referring to almost any human concern asks, "What's the use of it?" he means, "What is its immediate market value in term of dollars and cents?" And this type of man was quite effectually answered by the

It seems incredible that any Theory of Values will ever be formulated which shall establish a clear and ever be formulated which shall estabion a clear and uniform criterion of worth; a criterion which shall of the United States, and Shakespeare's plays.

But without pretending to give an exhaustive definition of what we mean by value we may say, with a fair hope of being understood, that the value of science may be regarded from two points of view. We may speak of the applications which depend upon it, and the effect of those applications in benefiting mankind. "This statement is obscure till we define "to benefit," but it is impossible
to define everything, there being only a finite number to define everything, there being only a finite number
of words in the language, and we shall assume that the phrase "to benefit mankind" is sufficicntly undertood.

This is the line that used to be adopted by seicentifie with the brutal question, "Whith's the use of it?" "They would stammer and hesitate and finally, with a look ties (say 0.10 per cent and under) of carbon monoxide, the author of this paper would say that it is largely a question of observation. The blood of the animal only slowly and to the extent that even after a long ime, one hour or more, the only effect in the animal time, one hour or more, the only effect in the animal may be a slight sluggishness or disinclination to when moving about or doing hard work, absorb much more oxygen and hence more carbon monoxide than when at rest, and may finally feel a slight or even a severe headache in the same gas mixture that is only slightly or not affecting the animals finally become very sick. It is not believed that any pronounced acclimatization effect is produced in an animal on a short exposure which would account for the apparent resistance. It must be remembered that a man is in an excellent position to determine effects upon himself long before distress occurs, in the case of small percentages of carbon monoxide.

When the carbon monoxide content of an atmosphere is raised from 0.10 per cent to say 0.15 or 0.20 per cent, the susceptibility of a canary or mouse to the gas is markedly increased, as judged by the
action of the animal, so much more than in the case action of the animal, so much more than in the case
of men that a canary especially may show distress in 5 minutes, while a man may require 30 or more minutes. A man, if he exposes himself as long as this, however, may finally become very siek, and if for longer periods, may become dangerously so.

The Bureau has compiled data from differen sources to show the effect produced on different percons by carbon monoxide. The fact is clearly brought out that the gas may affect different persons in a different manner. Long-standing after-effects produced in people by severe poisoning, although apparently rare, are by no means unknown. It appear to be the evidence usually that recovery from exposure is complete, but that in the case of some individuals long-standing after-effects may follow These after-effects on different people cannot be connected absolutely with any particular degree of exposure, such as, for example, one short exposure
to large percentages, repeated exposures to large percentages as usually happens in the case of blastfurnace gas, or slow exposure to collapse with small percentages of the gas, as in the case of miners exposed to the smaller percentages that are found in mine following explosions. In the case of the same individual the final blood saturation is what counts. The point is that different people may withstand different degrees of blood saturation. In the case of blast-furnace men, the same men may be exposed of blast-furnace men, the same men may be exposed
to collapse or severe temporary sickness time and again. Usually, as far as can be observed from their behavior, they retain their normal condition, although, as has been pointed out by Thomas Oliver, sever after-effects may linger for two years. This appears to be exceptional. An Illinois commission appointed to inquire into conditions around steel plants, found it hard to separate effects on steel workers produced by bad living conditions and those produced on some

of relief, mutter vague phrases about "growth of industry-wireless telegraphy-Pasteur and diseasemodern artillery" and the like. and all the time they were perfectly conscious of the fact that
study science for any of these reasons.

Nowadays they have grown more independent, and the President of a British Association section has been known to defend the study of pure mathematics for it own sake; while it has been said that a member of the Cavendish Laboratory once proposed the toast "Here's to the Electron Theory, and may it never be of any use to anybody!"

These are healthy symptoms. It is time we refused to view the universe, and all that therein is, through the spectacles of the commercial man. Let him continue to sell his oil and slaughter his pigs, and reserve his standards sell his oil and slaughter his pigs, an
of value for his fellow merchants.

Prof. A. G. Webster once remarked that a steam engine was to him an interesting example of the secon law of thermo-dynamics. The fact is that scientific research needs no justification on external grounds. Civilized man has a natural and insatiable curiosity concerning the laws and structure of the universe, and this mental hunger has as much right to satisfaction as physical hunger.

The mental satisfaction afforded by a theory which knits together a large body of facts is doubtless largely aesthetic. The perception of harmony and regularity in the operations of nature carries with it as intense a
f'eeling of pleasure as is evoked by a succession of beautiful harmonies in music. Man seeks instinctively for law and order. of the men by carbon monoxide, although they were
inclined to the view that carbon monoxide poisoning had considerable to do with the generally poor conof the gas in producing bad nervous disorders still remains somewhat obscure. Some do not believe the action so simple as to merely temporarily deprive the system of oxygen, as in the case of suffocation, although most of the good experimental evideneo points to this view. Somewhat analogous is the case of men who work at high altitudes or who suddenly ascend to extreme heights in balloons, where the oxygen tension is very low. Different individuals also doubt in cases both of carbon monoxide poisoning and oxygen deprivation by other causes, the idiosyncrasy of the individual plays an important part. Others have laid much stress on this point.

As regards acclimatization to the gas, it has been strikingly shown that guinea pigs may become immune. The compensation found in pigs has also been in part observed in men. The red-blood cells by the to compensate for those put out of action tinue without pronounced distress on the part of men is a uestion that requires investigation.

Repeated exposure to carbon monoxide may occur in the case of miners, in those who do the shot-firing. Blasting explosives always produce some carbon monoxide in coal mines. Men may return too quickly to the working face (before gases have disappeared), to examine their shot, and thus expose themselves to percentages, usually small, of the gas. poor, and where the working faces are too far ahead of the last breakthrough, contact with harmful of the last breakthrough, contact with harmful
percentages of carbon monoxide and other poisonous percentages of carbon monoxide and other poisonous
gases may follow. Miners at some mines frequently gases may follow. Miners at some mines frequently
go home sick from powder smoke. The general effect on them of such exposure cannot be anything but bad.

In the conduct of exploration work one sometimes hears it said that certain individuals of a party were able to withstand atmospheres that caused distress in other members of the same party. This may be true because some men are more affected than others by the same proportions of the gas, but one or two
other causes must be kept in mind. After-damp in different parts of a mine, sometimes in two places quite close together, may differ much in composition, to the extent that at one place a very small and insignificant amount of carbon monoxide might be present, while at another place, close y, a harmful proportion might exist. One person in a party unknowingly might encounter the latter atmosphere while his comrades do not. Another reason usually less apparent to an exploring party has to do with the fact that the amount of carbon monoxide absorbed depends, of course, upon the air breathed. A man at rest may breathe 7 or 8 liters of air per minute. 3 or 4 times that quantity. It follows that if one or more members of an exploring party work harder than others they will become poisoned more quickly than the others.

Science has done much for the imagination. Researches on the distances of the fixed stars revealed to us the scale. on which the universe is constructed. Wa realize that our planet is a speck of dust swimming realize that our planet is a speck of dust swimming
amid unthinkable immensities; and on the other hand, modern physics shows us that the finest grain of matter we can perceive holds within itself a multitude of complex systems whose properties are even now but dimly undertood

Whether or not these results influence commerce or industry, they are of the highest value. They enlarge man's mental outlook, which

It would be difficult to maintain that, as a nation, we amount to more than the ancient Greeks, in spite of their total lack of electric street cars and steam railroads, but if such an argument were undertaken, our best way of proving our case would be to point out the great superiority of our science. The mental and moral achievements of a people, much more than their com-
mercial and industrial greatness, determine their true worth and their influence on history.

Science, apart from its direct technical applications and the aesthetic pleasure it affords its votaries, is of the greatest value by reason of the intellectual temper, he habit of mind, that its study creates.

We are agreed that the present state of society is in many respects undesirable, and various panaceas have
been offered for the consideration of the publi:. They all labor under the same disad vantage -- there are not enough data. Before a satisfactory and permanently stabl state of society can be constructed, a whole host of 
preliminary problems must be seltled. Prof. MacDougall, in his very interesting work on Social Psychology, points this out quite clearly. We do not know enough about the complex actions and interactions of communitios of men to be able to frame laws with any communitios of men to be able to frame laws with any
permanent claims to value. The fringe of the subject permanent claims to value. The fringe of the subject
only has been touched. More work upon strictly scientific lines is needed.

Until the scientific spirit has thoroughly penetrated the borly of the peoplo, until they have learned to think without projudice, to disregard authority unbacked by reason, and to be critical in their examination of evidence, social reform must necessarily be a slow and halting process.

This is one reason why the dissemination of simply written accounts of scientific work is to be encouraged. We cannot all spend years in scientific study, but that is no reason why we should not largely share the advantages that a scientific training gives. It is possible to present all the great theories and results of science in a precise and accurate manner, which is novertheless simple enough to be understood by the average man. Such simple accounts, if sinecrely and competently done, aro capable of benefiting humanity to a greater extent than many highly technical and recondite papers enshrined in various "Proceedings" will ever do. Some branches of science are necessarily technical. Mathematical work would be unendurably prolix were the conventional shorthand not adopted, but nearly every other branch of science can bo simply and clearly expounded in a non-technical fashion.

When this is done on a large scale, when the ordinary man tries to keep an fait with scientifie work as naturally as he does with polities, murders and divorees, the result will prove that the value of seienee is sometling which eannot be overestimated.

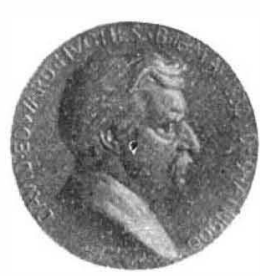

\section{The Hughes}

Dr. A. Graham Bell, LL.D., the distinguished inventor and physicist, has been awarded the Hughes medal, which is the gift of the Royal Society of London, for his share in the construction of the telephone receiver and invention of the telephone. The medal was founded under the terms of the will of Prof. D. E. Hughes, F.R.S., the inventor of the microphone, who in 1898 bequeathed the sum of $£ 4,000$ to the Royal Society, as well as similar amounts to the Institution of Electrical Engineers, London, and the Acarlémie des Science, Paris. No restriction of age or nationality was to weigh in the selection of any re(ipients.

Dr. Bell was born in Edinburgh, Scotland, March 3rd, 1847, son of Alexander Melville Bell, who, in 1870 bocame a lecturer on philology at Queen's College, Kingston, Ontario, removing in 1881 to Washington D. C., where he devoted himself to the education of deaf mutes. Graham Bell was educated at Edinburgh

\section{The Glow of Sulphur*} By W. H. Watson

Although not mentioned in the majority of textbooks, the fact that sulphur under certain circumstances exhibits a glow or "phosphorescence" has been frequently recorded. The method of obtaining the glow was described by Berzelius in his "Lehrbuch" glow was described by Berzelius in his "Lehrbuch"
(5th edition, vol. i., p. 185), and since then several (5th edition, vol. i., p. 185), and since then several
investigators have turned their attention to the matter, but without arriving at an explanation of the phenomenon. The idea has been suggested that the glow wa accompanied by the formation of a lower oxide of sulphur, possibly a monoxide, SO, but attempts to obtain such a body by Heumann (Ber. xvi., 139), O. Jacobsen ( $e r$. xvi., 478), and also by the writer, have proved unsuccessful. Experiments upon the oxidation of sulphur at low temperatures by Moissan (Comptes of sulphur at low temperatures by Moissan (Comptes
Rendus, 1903, xxxvii., 547) also lend no support to Rendus, 1903, xxxvii., 547) also lend no support to the idea. At the suggestion of Prof. H. B. Baker, to whom the writer desires to express his indebtedness,
a further investigation of the phenomenon was underakien with the results set forth below.

In the paper by Heumann referred to above, the author describes various methods of obtaining the glow, the most successful of which appears to be that of placing sulphur on a shallow tray supported above the bottom of an iron air-bath heated to about 240 degrees, and allowing a current of air to pass over the molten sulphur. When the conditions are properly rogulated, a large flame, differing in color from the usual blue flame of burning sulphur and also in the fact that it is relatively cold (see also Baker, Journ ('hem. Soc. Trans., 1900, lxxvii., 646), can be obtaine and maintained for a considerable time. The author states that the slow combustion is accompanied by a curious smell which he compares to ozone or camphor

These facts have been confirmed by the present writer, who found that the glow invariably exhibite itself as a curious luminous flicker over the heated base and adjacent parts of the sides of the oven, but neve on the surface of the sulphur. Further experiment were made by means of an apparatus similar to that described below.

A piece of glass tubing, 40 to 50 centimeters long and about 1 centimeter bore, was bent as shown in the sketch, and had a narrow side-tube sealed in at $C$. Some pure re-crystallized sulphur, which had previously boen kept melted for some time, was placed in the part $A$, while $B$ was inclosed in an air-bath kept at 100 to $A$, while $B$ was inclosed in an air-bath kept at 100 to
120 deg. Cent. The sulphur was maintained at about 250 degrees, while a slow current of pure dry air wa passed throngh the apparatus, the side-tube $C$ boin closed. So long as the sulphur was kept below it ignition-point, no luminosity could be observed on *Reproduced from the Chemical_News.

\section{Award to Dr. Alexander Graham Bell}

\author{
By T. E. James
}

University and London University. Going with his father to Canada in 1870, he, two years later, was appointed a professor of vocal physiology in the Boston University.

Bell for many years was Regent of the Smithsonian Institution in Washington. He has taken an active interest in phonetics, and has invented a machine called the graphophone, allied to the phonograph, for recording and reproducing sound. This instrument has come into use for teaching phonelics in American schools and colleges. In his later years ho has experimented on the problem of flying, and has invented special types of man-lifting kites. His inventions and experiments have shown much originality and his scientific contributions, especially to applied science, have great merit.

The tribute paid by the late Sir William Preece, F.R.S., to Bell's services may here be recalled. Writing in 1878, he said: "The phonograph is the outcome of

the surface of the sulphur, but the air current became charged with a cloud of fine particles which were carried along the tube and not completely deposited before reaching the open end. In the portion of the tube within the air-bath, extending for some centimeters from the end nearer the melted sulphur, a steady glow could the onderved, which, however, ceased if by any chance be observed, which, however, ceased if by any chance
the liquid sulphur became ignited. The glow could be produced at any part of the tube $B$ by heating gently at that part and allowing the rest to remain cool, even when $B$ was of considerable length. By using a mixture of nitrogen and air a somewhat brighter glow was obtained, but the glow completely ceased if pure nitrogen were employed. In this latter case however, it was possible to obtain a glow by introducing air through the side-tube $C$. It would therefore seem unlikely that the glow is connected with preliminary action of oxygen on the heated sulphur.

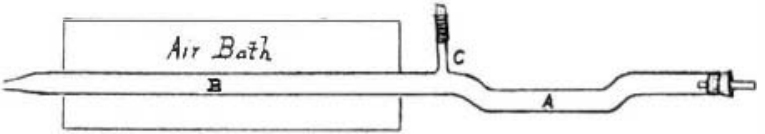

If the air current after passing over the heated sulphur were filtered through a tube filled with recently ignited asbestos no glow whatever could be obtained in $B$, but the glow reappeared when the asbestos was removed. Similar results were obtained if cotton-wool or pieces of moist stick potash were used instead of asbestos. Bubbling the air through water was also effective, and a quantity of colloidal sulphur collected in the water

In another series of experiments the gases escaping from the end of the tube in which the glow was taking place were led through a tube immersed in liquid air A small amount of solid sulphur dioxide was collected, and in some cases a liquid. This latter, however, contained no sulphur compound other than a trace of sulphur dioxide, as on careful evaporation and bubbling the resulting gas through fuming nitric acid or a solution of potassium permanganate, no sulphuric acid was obtained. The gas contained about 40 per cent of free oxygen, and the residue appeared to be nitrogen and probably some argon. Similar results were obtained if the gases immediately after leaving the heated sulphur and without allowing the glow to occur, were treated in the same way. In all cases the gas which escaped liquefaction by the liquid air was quite odorless.

There is therefore no direct evidence that an appreciable amount of an oxide of sulphur other than dioxide is formed at any stage. Heumann arrived at a similar conclusion from an analysis of the gases escaping from glowing sulphur. The glow appears to be (a)used by the oxidation of the particles of finely-divided sulphur resulting from the cooling of the air which has passed over the heated sulphur, and this viow is" in the articulating telephone. Though several have added their share in perfecting the 'far-speaker,' there is no name in connection with it that will shine with greater brilliancy than that of Alexander Graham Bell. His father's occupation as a vocal physiologist, led him to study the vocal organs and the production of sound. Helmholtz's researches led him to investigate electricity and its application to telegraphy. The desire to increase the capacity of wires for the conveyance of messages led him to devise systems of multiple telegraphy, and this by steady and sensible degrees, led him to articulate telephony. We have a motable example of the modern mothod of research, whore imagination suggests experiment, and experiment by evolution produces growth and perfection. The telephone will always be associated with B(1l's name, and it will remain one of the marvols of this marvelous age, while its chief marvel will be its beautiful and exquisite simplicity."

harmony with the observations recorded both hero and in the records of earlier investigators. If this finely-divided sulphur is the result of some such reactions as the following $-2 \mathrm{~S}+\mathrm{O}_{2}=2 \mathrm{SO}$, then $2 \mathrm{SO}=$ $\mathrm{SO}_{2}+\mathrm{S}$, the intermediate product must have a merely transient existence, and its presence would not be shown by chemical tests.

The finely-divided sulphur not only undergoes oxidation at a comparatively low temperature, but attacks copper and silver at the ordinary temperature with the production of black films of sulphide. Experiments made in order to discover whether the particles were electrified or not, failed to show the existence of a charge. Air containing the finely-divided sulphur led through a trke containing an insulated piece of copper-foil connected with a delicate electroscope did not discharge the latter, whether the instrument carried a positive or negative charge. In other experiments the stream of finely-divided sulphur passed between two long strips of platinum foil, insulated and connected to opposite terminals of a small induction coil. Some 5 to 10 milligrammes of sulphur deposited on the plates in the course of an hour, but although the amounts deposited on the two plates were generally unequal, the variation was not large, and, moreover, not constant. On the whole, the results obtained were not decisive.

Summarizing the results obtained, it may therefore be stated that when air passes over sulphur heated to a temperature below its ignition-point, the air bocomes charged with sulphur vapor, which, as the temperature falls, separates as a mist or cloud of very
small particles. The oxidation of this finely-divided sulphur gives rise to the phenomenon of the glow or "phosphorescence," but there is no evidence that at any stage any other oxide than sulphur dioxide is formed.

\section{Indian Corn in the Far East}

Consul General anderson, stationed at Hong Kong, calls attention to an economic change of the utmost importance now in progress in the Far East, viz., the introduction of maize as a formidable competitor of the hitherto universal rice. Indo-China and the Philippines have already developed the cultivation of this grain to an extent which has affected international trade in the East and resulted in great benefit to the peoples concerned Maize has made less rapid progress in China. The cultivation of maize in the Philippines results from an energetic campaign of education on the part of the Bureau of Agriculture. In most parts of the islands tivo or even three crops can be produced annually. The recent threatened rice famine in the Philippines, which impelled the goveriment to import large quantities of rice and sell it below cost, emphasizes the urgent need of a diversification of the native diet. 